\title{
渤海湾盆地早第三纪非海相钙质超微化石的 锶同位素证据
}

\author{
刘传联 \\ (同济大学海洋地质开放实验室, 上海 200092; \\ 胜利石油管理局, 东营 257064)
}

\author{
成金荃荣 \\ ( 同济大学海洋地质开放实验室, 上海 200092)
}

\section{关键词 锶同位素 钻质超微化石 早第三纪}

渤海湾盆地早第三纪沙河街组在沉积过程中有无 “海侵”, 一直是地学界争论的问题之 一. 争论的原因是在这套地层中既存在典型的陆相化石 (如介形虫、腹足类及轮藻等) 又有一 些所谓 “海相性”化石 (如有孔虫、鱼类、钲质超微化石等)．其中尤以钻质超微化石最为引人 瞩目 ${ }^{[1 \sim 3]}$, 因为尽管该类生物现代有一个属 (Hymenomonas) 生活在淡水中, 但其不具钻质骨骼 而无法保存为化石, 故一般认为钙质超微化石为典型的海相化石. 本文无意再从这些化石的 属种组成、形态特征及生态分布对上述问题进行深究，而利用近年来发展迅速的锶同位素分析 方法, 以沙河街组钻质超微化石为材料, 从地球化学的角度来探讨该类化石生活的环境.

\section{1 材料与方法}

样品取自山东济阳坳陷 6 个钻孔的沙河街组 (图 1). 通过分析发现钙质超微化石主要分 布在沙河街组一段和四段, 其数量丰富, 但属种单调, 主要为 Reticulofenestra bohaiensis ${ }^{[3]}$ (图 2). 产钙质超微化石的岩性主要有钙质页岩、灰色泥灰岩及灰褐色泥岩, 其中以其“黑”、“白”相间 韵律纹层的钻质页岩中最为丰富, 灰白色的钙质薄层几乎全部为钙质超微化石 (图 2), 而暗色 的泥岩层则为沟鞭藻及其他有机质, 不含超微化石. 首先对每个样品在偏光显微镜和扫描电 子显微镜下进行观察, 然后挑选了 10 个超微化石最丰富、成岩作用影响最小的样品进行锶同 位素分析. 对于钙质页岩, 用锋利的刀片刮取灰白色的钻质薄层, 留意剔除混人其中的暗色粉 末, 以保证样品的纯度. 而对于泥灰岩、泥岩则取混合样, 全部样品均取 $1 \mathrm{~g}$. 钲质超微化石的锶 同位素由中国地质科学院地质研究所锶钿组用 MAT-260 型质谱仪测试完成, 测定精度一般在 $0.01 \% \sim 0.05 \%$ 之间, 标准偏差为 $4 \times 10^{-5} \sim 4 \times 10^{-4}$.

\section{2 分析结果与讨论}

10 个钙质超微化石样品的锶同位素组分析结果如表 1 所示, 从中可以看出沙一段钙质超 微化石的 ${ }^{87} \mathrm{Sr} /{ }^{86} \mathrm{Sr}$ 比值为 $0.71121 \sim 0.71168$, 平均 0.71146 , 沙四段钻质超微化石的 ${ }^{87} \mathrm{Sr} /{ }^{86} \mathrm{Sr}$ 为 $0.71118 \sim 0.71184$, 平均 0.71151 .

现代研究表明, 生物碳酸盐骨骼中的 ${ }^{87} \mathrm{Sr} /{ }^{86} \mathrm{Sr}$ 比值与其生活的海水保持平衡, 地质历史上 


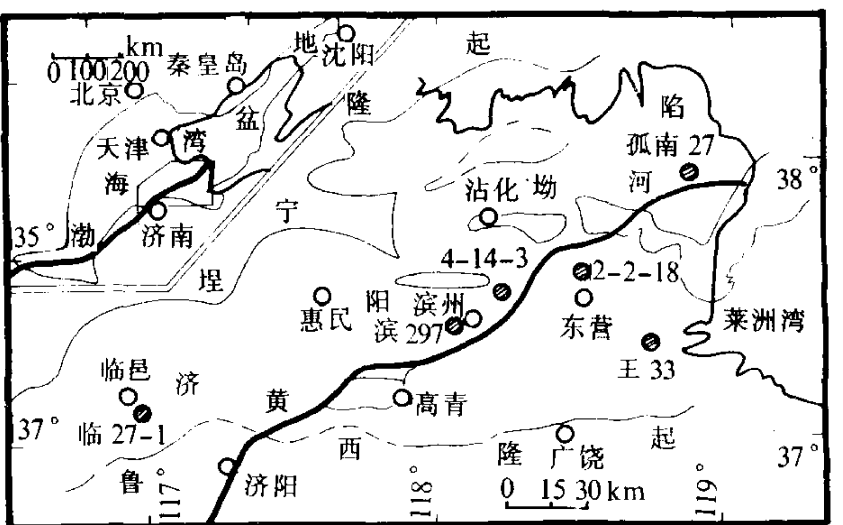

图 1 样品地理位置图

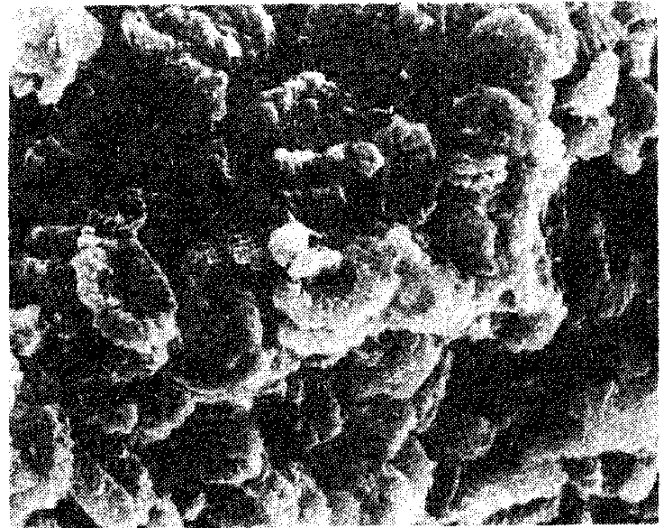

图 2 沙河街组钲质超微化石 (Reticulofenestra bohaiensis)

孤南 27 井,沙一段, $2157.3 \mathrm{~m} . \times 6000$

表 1 沙河街组钲质超微化石 ${ }^{87} \mathrm{Sr} /{ }^{86} \mathrm{Sr}$ 比值

\begin{tabular}{|c|c|c|c|c|c|c|}
\hline 钻孔 & 井深 $/ \mathrm{m}$ & 层位 & 年代 & 岩性 & ${ }^{87} \mathrm{Sr} /{ }^{86} \mathrm{Sr}$ & 标准偏差 \\
\hline 孤南 27 & 2157.3 & 沙一段 & 渐新世 & 钙质页岩 & 0.71154 & 0.00040 \\
\hline 孤南 27 & 2157.8 & 沙一段 & 渐新世 & 䥻质页岩 & 0.71168 & 0.00019 \\
\hline 孤南 27 & 2158.0 & 沙一段 & 渐新世 & 钻质页岩 & 0.71154 & 0.00023 \\
\hline 孤南 27 & 2158.3 & 沙一段 & 渐新世 & 钙质页岩 & 0.71126 & 0.00004 \\
\hline 孤南 27 & 2161.6 & 沙一段 & 渐新世 & 钲质页岩 & 0.71145 & 0.00010 \\
\hline $4-14-3$ & 1357.5 & 沙一段 & 渐新世 & 钙质页岩 & 0.71121 & 0.00021 \\
\hline $2-2-18$ & 1850 & 沙一段 & 渐新世 & 灰褐色泥岩 & 0.71150 & 0.00014 \\
\hline 临 27-1 & 2452 & 沙一段 & 渐新世 & 灰褐色泥岩 & 0.71152 & 0.00004 \\
\hline 滨 297 & 1321.5 & 沙四段 & 始新世 & 灰褐色灰岩 & 0.71118 & 0.00009 \\
\hline 王 33 & 1973.3 & 沙四段 & 始新世 & 钙质页岩 & 0.71184 & 0.00042 \\
\hline
\end{tabular}

海水的 ${ }^{87} \mathrm{Sr} /{ }^{86} \mathrm{Sr}$ 比值在不断变化, 但任一时期全球海水的 ${ }^{87} \mathrm{Sr} /{ }^{86} \mathrm{Sr}$ 比值则是均一的 ${ }^{[4]}$; 同时人们 还发现由于河、湖水中的锶与海水中的锶来源物质的不同, 造成河、湖水的 ${ }^{87} \mathrm{Sr} /{ }^{86} \mathrm{Sr}$ 比值明显 高于海水,如现代海水的 ${ }^{87} \mathrm{Sr} /{ }^{86} \mathrm{Sr}$ 比值为 0.709 , 河水中的 ${ }^{87} \mathrm{Sr} /{ }^{86} \mathrm{Sr}$ 约为 $0.711^{15}$. 另外, 海水中 锶的浓度也与河、湖水相差悬殊, 如新生代海水中锶含量在 $10^{2} \sim 10^{3} \mathrm{mg} / \mathrm{L}$ ，之间 ${ }^{[6,7}$, 河、湖水中 锶含量多在 $10^{\circ} \sim 10^{2} \mu \mathrm{g} / \mathrm{L}$ 之间 ${ }^{[!]}$, 两者相差 3 个数量级. 如果海水与湖水相混, 水体仍反映海 水 ${ }^{87} \mathrm{Sr} /{ }^{86} \mathrm{Sr}$ 的比值, 所以无论正常海相还是与海水有关联的海陆过渡相化石都应呈现海水的 ${ }^{87} \mathrm{Sr} /{ }^{86} \mathrm{Sr}$ 比值. 如果沙河街组钙质超微化石生活的环境是海或者与海有某种联系的话, 根据上 述锶同位素变化的特点, 那么其 ${ }^{87} \mathrm{Sr} /{ }^{86} \mathrm{Sr}$ 比值就应与同时期海水的 ${ }^{87} \mathrm{Sr} /{ }^{86} \mathrm{Sr}$ 比值相同. 沙一段 沉积的时代为渐新世, 沙四段沉积的时代为始新世 ${ }^{[8]}$. 通过 Koepnick 等所作的新生代海水 ${ }^{87} \mathrm{Sr} /{ }^{86} \mathrm{Sr}$ 曲线可以看出渐新世海水的 ${ }^{87} \mathrm{Sr} /{ }^{86} \mathrm{Sr}$ 为 $0.7076 \sim 0.7084$, 而始新世海水 ${ }^{87} \mathrm{Sr} /{ }^{86} \mathrm{Sr}$ 约为 $0.7076 \sim$

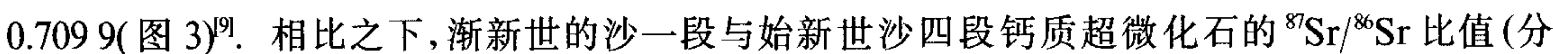
别为 $0.71121 \sim 0.71168$ 和 $0.71118 \sim 0.71184$ ), 都明显高于同时期的海水的 ${ }^{87} \mathrm{Sr} /{ }^{86} \mathrm{Sr}$ 比值, 所以 渤海湾盆地早第三纪沙河街组钻质超微化石生活的环境决不是海相, 与海也没有任何联系, 而是一种陆相环境, 其出现也许与水体的化学条件有关. 


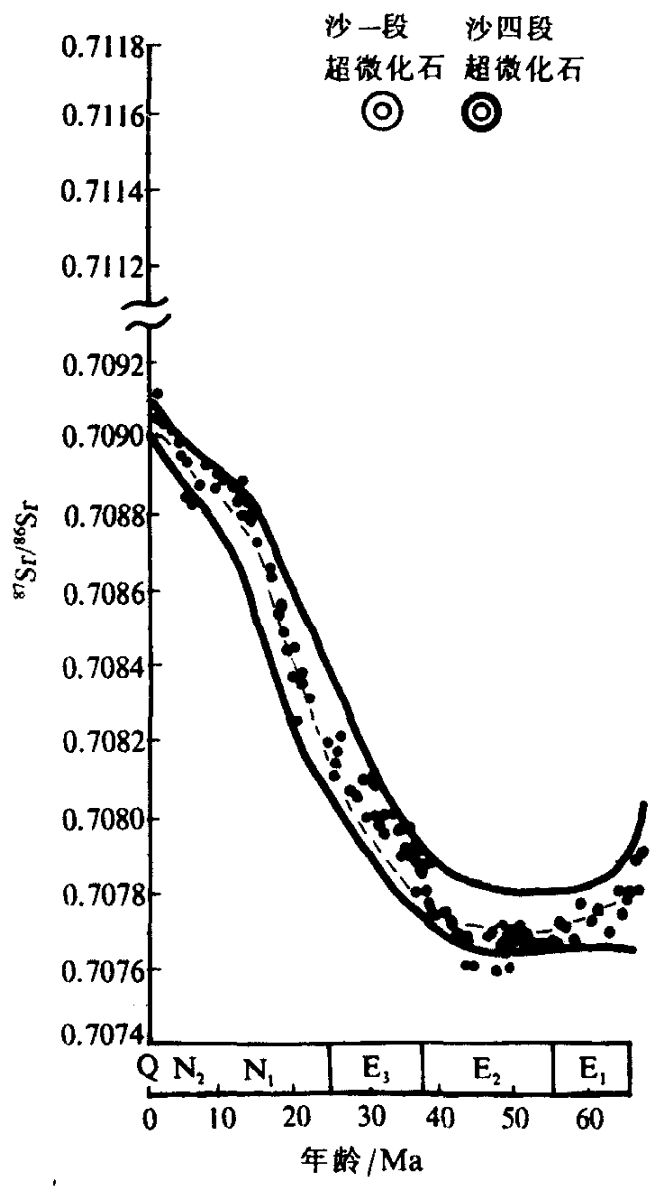

图 3 新生代海水 ${ }^{87} \mathrm{Sr} /{ }^{86} \mathrm{Sr}$ 曲线及沙河街组样品在其中的位置

致谢 本文承汪品先教授指导和审阅, 徐金锂高级工程师提供样品, 作者在此深表谢意。

\section{参考 文 献}

1 于 众. 我国辽河地区发现䥻质微型化石. 石油勘探与开发, 1982, (3): 82

2 郝诒纯, 李㟟生. 渤海沿岸及邻近地区早第三纪钻质超微化石的发现及其意义. 科学通报, 1984, 29(12): $741 \sim 745$

3 钟微春, 钟石兰, 弗轩冬等. 渤海清盆地沙河街组一段颗石菓类化石及其沉积环境. 微体古生物学报, 1988, (2): $145 \sim 151$

4 Elderfield H. Strontium isotope stratigraphy. Palaeogeogr, Palaeoclimatol, Palaeoecol, 1986, 57: 71 90

5 Wadleigh $\mathbf{M}$ A, Veizer $J$, Brooks $\mathbf{C}$. Strontium and its isotopes in Canadian rivers: fluxes and global implications. Geochim Cosmochim Acta, 1985, 49:1 $727 \sim 1736$

6 DePaolo D J, Ingram B L. High-resolution stratigraphy with strontium isotopes. Science, 1985, 227:938 941

7 Koepnick R B, Burke W H, Denison R E et al. Construction of the seawater ${ }^{87} \mathrm{Sr} /{ }^{86} \mathrm{Sr}$ curve for the Cenozoic and Cretacoous. Chem Geol, 1985, 58: $55 \sim 81$

8 王秉海,钱 凯. 胜利油区地质研究与勘探实践. 山东东营: 石油大学出版社, 1992. 53

9 Koepnick R B, Denison R E, Dahl D A. The Cenozoic seawater ${ }^{87} \mathrm{Sr} /{ }^{86} \mathrm{Sr}$ curve: data review and implications for correlation of marine strata. Paleoceanography, 1988, (3): $743 \sim 756$ 